\title{
NEIZRAZITO USVAJANJE JEZIKA
}

\author{
Sandro Skansi \\ Visoko učilište Algebra, Zagreb, Hrvatska \\ sandro.skansi@racunarstvo.hr
}

Primljeno: 4. 4. 2016.

\begin{abstract}
U ovome tekstu istražujemo ulogu neizrazitosti $i$ nužnih svojstava $u$ usvajanju jezika. Kroz jezične igre definiramo kontekst i njegova esencijalna svojstva i analiziramo neke klasične probleme u filozofiji jezika iz perspektive deskriptivizma, ali s neizrazitim grozdovima opisa. $\mathrm{Na}$ kraju analize dajemo prijedlog sustava s kompleksnim vrednovanjem koji je u stanju zaključivati s kontekstualno nerazlikovnim elementima. Punu formalizaciju ovog sustava ostavljamo za nastavak istraživanja.
\end{abstract}

Ključne riječi: usvajanje jezika, neizraziti skupovi, nerazlikovni elementi skupa, kontekstualizam, nužna svojstva

\section{Uvod}

Usvajanje jezika jedno je od temeljnih filozofijskih ali i metodičkih pitanja koje je prvi, u današnjem obliku, postavio Ludwig Wittgenstein u svojim Filozofijskim istraživanjima (Wittgenstein, 1998, par. 2). Wittgenstein je stipulirao tzv. jezične igre kao okružje usvajanja jezika. U prikazu komunikacije zidara pokazao je kako ne postoji jedan konkretan način upotrebe tzv. singularnih termina, odnosno jezičnih izraza koji se doživljavaju kao jednoznačni. Oni mogu biti referencijalni i direktno referirati na predmet ili mogu biti deskriptivni pa opisom hvatati referenciju ili mogu biti imperativni zadaci koji ne referiraju uopće na predmet nego na neki problem, pa se zaključuje na predmet za njegovo rješavanje. Ono što je Wittgenstein izvukao, kao jedinu preciznu definiciju, da je značenje neke riječi njena upotreba u jeziku, u kontekstu određene jezične igre gdje sudionici znaju pravila igre (odnosno upotrebe riječi) ili se na njih utreniravaju (ako su novi igrači igre) (Wittgenstein, 1998, par. 43). 
Ideja da je upotreba jezika prvenstveno zadana kao igra, odnosno kao (potencijalno) adversarijalna situacija (Russell i Norvig, 2009), predstavlja dosta jaki zaokret od shvaćanja jezika kao sredstva komunikacije, jer je komunikacija u svojoj prirodi kooperativna situacija, no to shvaćanje obuhvaća neke iskonske, primarno adversarijalne upotrebe jezika poput svađanja, laganja ili nagovaranja. Ove upotrebe jezika u stvarnosti su bitno češće nego strogo faktično-komunikativne upotrebe jezika.

Ono što je različito $u$ adversarijalnom shvaćanju nasuprot kooperativnom je ideja usvajanja jezika. U kooperativnom kontekstu, inicijacija novog govornika ima jednu blagonaklonu komponentu koja čini pitanje dobrog usvajanja jezika bitno manje specifičnom, jer se novog govornika može voditi i pokazivati mu predmete imenujući ih (ili opisujući) ostenzivnim definicijama.

Cilj je našeg istraživanja ponuditi formalni okvir za razumijevanje referencije kada se radi o jezičnim izrazima kojima se hvata neki fenomen (ovo ćemo nazivati zahvatom). Njihova neizrazitost stvara poteškoće, no temeljem postuliranja hijerarhije nužnih svojstava problem postaje razumljiviji. Kako ćemo argumentirati, neizrazitost se time može smanjiti. Razlikovanjem dviju vrsta neizrazitosti koje su povezane, ali ipak zasebne, ovaj se fenomen može adekvatno opisati, čime se otklanja još jedan sloj nepreciznosti.

Značenje ovog istraživanja za odgojnu teoriju je dvojako. Prvo, naše istraživanje pokazuje koliko se fenomeni koje se tradicionalno predstavlja kao bulovske (s dodatnim problemima i kompleksnim iznimkama) pojednostavljuju kada se sagledavaju u neizrazitim formalizmima, čime postaju i razumljiviji i jednostavniji. S druge se strane razmatra problem javljanja neizrazitosti i suprapozicije uslijed nemogućnosti točnog specificiranja dimenzija odnosno broja parametara za njihovu točnu pripadnost s jedne, i njihovu individuaciju s druge strane. Rješenje ovog problema leži $u$ istraživanju neizrazitih sustava s kompleksnom semantikom, čime se pruža formalni okvir za razumijevanje neizrazitih fenomena u usvajanju jezika i jezičnog izražavanja, kao temelja usvajanja konkretnih znanja iz nekog drugog područja.

\section{Neizrazitost}

Usvajanje jezika je inherentno neizraziti proces. Neizrazita logika u svojoj se osnovnoj varijanti može shvatiti kao pitanje članstva u ne- 
izrazitim skupovima (Hayek, 1998), pri čemu se gleda da vrijednosti karakteristične funkcije (koje se u neizrazitoj logici nazivaju funkcijama članstva (Ross, 2010)) mogu biti bilo koja vrijednost u intervalu od 0 do 1 , i da svaka točka ima svoju vrijednost članstva.

U kontekstu usvajanja jezika, ovo znači da se element jezične igre ne usvaja s bulovskom vrijednosti, nego s nekim neizrazitim koeficijentom, koji je podložan promjenama, ali za razliku od probabilističkih koeficijenta ne postoji trenutak u kojem vrijednost između 0 i 1 »kolabira« u 0 ili 1. Primjer probabilističke situacije je izjava »sutra će se Petru Petroviću dogoditi prometna nesreća « kojoj se daje vrijednost od 0.04 (odnosno 4\%). Prekosutra će ta vrijednost biti ili 0 ili 1, ovisno o tome što se stvarno dogodilo. Neizrazite situacije su slične, ali nemaju ovaj kolaps, no imaju reviziju (što do trenutka ispunjenja imaju i probabilističke). Primjer neizrazite situacije je izjava »Ovo je pas sličan onom kojeg smo sreli jučer u parku«. Ako se ovoj izjavi daje vrijednost 0.89 , tada ta vrijednost neće nikada kolabirati u 0 ili 1 . Naglasak ovdje nije na vremenu koliko na metafizičkim značajkama fenomena.

Ako se promatra izjava »Sutra će padati kiša« i daje joj se vrijednost 0.9 , to može djelovati kao tipično probabilistička izjava. No sam pojam padanja kiše je neizraziti. Koliko jako kiša mora padati da bismo to proglasili istinitim (odnosno da bismo kolabirali u 1)? Je li jedna kap na sat vremena dovoljna? Dvije? Ovime dolazimo do vrlo važne relacije između probabilističkih i neizrazitih situacija. Probabilističke situacije predstavljaju idealizaciju nesigurnosti, ali moraju po svojoj prirodi koristiti neizrazite elemente za opis svijeta.

Ovdje je naglasak na »opisu svijeta«. Jezik je glavno sredstvo realizacije između strogo konceptualnih tvorevina (statistike, izračuna, brojeva) i stvarnog svijeta: da bismo rekli nešto o uzgoju jabuka što ima statističku ili prediktivnu snagu, moramo stvoriti podatke iz fenomena. Najjednostavniji primjer je brojanje. Općenito govoreći, brojanje se može shvatiti kao poseban slučaj ustanovljavanja svojstava, a fizikalne pojave nisu kategorizirane kao jezične i pojmovne. Ovo je najbolje ilustrirano na Wittgensteinovom primjeru s pet crvenih jabuka (Wittgenstein, 1998, par. 1). Jezična igra ustanovljavanja svojstava je efektivno podatkovna kategorizacija: pripada li taj »zahvat« predmeta pojmu pet i pripada li taj »zahvat« (odnosno svaki član zahvata) pojmu crveno. Ovdje namjerno koristimo izrazito platonistički rječnik. Uočimo da pet crvenih jabuka nisu crvene ako je jedna zelena, kao ni to da jedna crvena jabuka i jedna zelena jabuka ne čine »u prosijeku« jednu žutu. 


\section{Nužna svojstva}

Svako svojstvo ima pravilo po kojemu se neki predmet ili zahvat predmeta prihvaća u to svojstvo, ali ovo nije bulovski da/ne kriterij. Rubni slučajevi su »donekle« u redu, a čak i ovaj »donekle« je pitanje stupnja. Moguće je hipotetizirati da postoji nešto, neko podsvojstvo kojeg imaju svi predmeti koji pripadaju nekom svojstvu. Nadalje, možemo prihvatiti da je ovo podsvojstvo neizrazito, ali u manjoj mjeri nego osnovno svojstvo (jer bi inače bilo manje pouzdano nego osnovno svojstvo, pa bi bilo beskorisno kao pomoćni alat).

Ova se svojstva nazivaju nužnim ili bitnim svojstvima. Tradicionalno se smatralo da su nužnost, apriornost i analitičnost različita lica istog pozadinskog fenomena. Prvi udar na ovo shvaćanje došao je u Kantovoj Kritici čistog uma (Kant, [1787] 2007), gdje je pokazano da su moguće sintetičke propozicije a priori. Kripke (Kripke, 1980) je dao primjer za nužne propozicije a posteriori, u obliku nužnih svojstava za identitet. Primjer ovog je propozicija »ovaj stol je nužno od drva«. Kripke naglašava da je moguće napraviti isti takav stol od plastike, ali nije moguće napraviti taj stol od bilo kojeg drugog materijala, jer bi to bio drugi stol, a ne taj stol. Pitanje razlike između analitičkih i sintetičkih propozicija, odnosno opovrgavanje razlika bilo je centralno u Quineovom radu (Quine, 1980), no za naš rad ovo nije bitan argument, posebno radi tipa argumentacije koji se koristi.

Kao što smo već napomenuli, kada predmet potpada pod neko (kompleksnije) svojstvo $S$, skloni smo interpretaciji da taj predmet ima neko podsvojstvo $P$ i da vrijedi $P x \rightarrow S x$ (ova implikacija karakterizira nužna svojstva). Uočimo da ovdje ne govorimo direktno o nužnim svojstvima predmeta kao predmeta nekog tipa, nego o nužnim podsvojstvima za neko svojstvo. Ovo glavno svojstvo može biti »biti čaša« ili »biti čekić«, ali s obzirom da nužno podsvojstvo mora biti izrazitije od svojstva, slijedi da su sva »konačna« odnosno svagdašnja svojstva nužno najneizrazitija, jer se nalaze na vrhu tih lanaca podsvojstava. Ovo odgovara intuiciji jer smatramo da znanost koja proučava skrivena podsvojstva uistinu jest preciznija i izrazitija nego svakidašnji jezik.

Ideja strojnog učenja kao temeljna metoda učenja stroja jezičnom procesiranju također uvelike ovisi o bitnim podsvojstvima za neko svojstvo. Načelno, svaka metoda strojnog učenja iz označenih primjera je klasifikacija (Flach, 2012), a svaka klasifikacija je klasifikacija u skup. Problem je što svi ovi skupovi moraju biti čvrsti nakon klasifikacije. 
Drugim riječima, oni su postavljeni kao probabilistički jer se klasificira s određenom pouzdanošću, ali se kasnije ova pouzdanost kolabira u 0 ili $1 \mathrm{~s}$ obzirom na prihvaćeno članstvo u tom skupu.

Ovo je u praktičnom smislu dobar pristup, no on ima jednu objektivističku crtu koja je u suprotnosti s kompetitivnim usvajanjem jezika: u jeziku je česta pojava dvoznačnosti, ali i »navlačenje« referencije, odnosno da od dvoje govornika koji oboje koriste dio značenja iz neizrazite zone, jedan koristi u smislu 0 , a jedan u smislu 1. Proturječje koje iz toga slijedi ne eksplicira se odmah, nego može do daljnjeg ostati nederivirano. Nadalje, ovo proturječje nije jako. Ovo »hvata« ono što intuitivno doživljavamo kao »više« netočno ili »manje« netočno u jeziku. Dobar primjer toga je da smatramo malo netočnim kada kažemo da je rajčica povrće, a bitno više netočnim kada bismo tvrdili da je rajčica dio automobila. Ovo može djelovati kao trivijalan primjer, ali pokazuje da je naš tretman jezika u svojoj osnovi neizrazit, ali da su nužna svojstva izrazitija od njihovih nadsvojstava. Štoviše, ovo je nužno svojstvo nužnih svojstava, jer ako ne bi bila izrazitija od (moguće) kontingentnih nadsvojstva, po definiciji nužnih svojstava ne bi bila nužna svojstva.

\section{Uspješnost referencije i opisa}

Bertrand Russell ponudio je svoju teoriju određenih opisa još u radu On Denoting (Russell, 1905). Prema Russellovoj teoriji, singularni termini imaju prvenstveno opisnu ulogu, odnosno oni su tek parafraza opisa. Ovaj opis uključuje uvjete postojanja i sam opis, koji se onda atribuiraju predmetu na kojeg se želi referirati, i njihova istinitost utvrđuje referenciju. Na ovaj način se slažu tzv. »grozdovi opisa« koji se sastoje od implicitnih i eksplicitnih opisa i koji načelno jednoznačno izoliraju referenta svakog singularnog termina. Bilo koja neuspjela referencija je tada nedovoljna specifikacija opisa (ili pretpostavljanje da su iste neizrečene komponente opisa koje se kod sugovornika u stvarnosti razlikuju ili su odsutne), dok je bilo koja uspješna referencija uspješna zbog točnosti opisa. Russell je ovdje pretpostavljao bulovsko vrednovanje grozdova opisa kao veliku konjunkciju.

Keith Donnellan u svome je radu Reference and Definite Descriptions (Donnellan, 1966) napao ideju da je uspješna referencija uvjetovana točnosti opisa. Njegov argument je da izraz »Onaj čovjek koji drži Martini« može uspješno referirati na čovjeka koji pije votku iz čaše za 
Martini u kutu. Ključni naglasak ovdje je ne samo na pojavu da samo »većina« opisa u grozdu mora biti istinita, nego da oni imaju određene pondere.

Uzmimo dvije rečenice:

(S1) »Onaj pas koji drži votku u čaši za Martini«

(S2) »Onaj čovjek koji drži Martini«

$S 1$ je u određenom smislu precizniji od $S 2$, jer obje rečenice imaju jednako neistinitih dijelova ('pas' umjesto 'čovjek' u prvoj, i 'Martini' umjesto 'votka' u drugoj), no prva rečenica je preciznija utoliko što spominje čašu za Martini kao locus referencije a ne 'Martini', koji se tek uz pomoć (netočne ali prirodne) pozadinske premise »Martini se toči u čaše za Martini, a u čašama za Martini servira se samo Martini« pretvara u referirajući izraz (zato što referencija uspijeva vizualno, temeljem čaše). Usprkos svemu, ne bismo se složili da je $S 1$ preciznija, jer je pogreška bitno veća ako tvrdimo za čovjeka da je pas, nego ako tvrdimo za bezbojnu tekućinu na drugom kraju sobe da je Martini, a u stvarnosti je votka.

Pitanje se postavlja kako tretirati ove pojave i je li problem, kako Donnellan kaže (Donnellan, 1972), u brkanju dvaju načina na koje singularni termini ostvaruju referenciju. Naša teza je da je problem u korištenju izrazitog razmišljanja unutar teorije opisa. Neizrazitost sa svojim razinama povjerenja načelno bi riješila problem. No postoji jedan segment koji ne bismo uhvatili koristeći samo neizrazitost.

\section{Jezična suprapozicija i dimenzionalnost jezika}

Pitanje koje se postavilo kao razlika između $S 1$ i $S 2$ mora se shvatiti ne samo u kontekstu neizrazitosti nego i u kontekstu suprapozicije. Iz perspektive govornika koji uspijeva odnosno ne uspijeva postići referenciju, razlikujemo dva fenomena:

(F1) čovjek $\neq$ pas

(F2) votka u čaši za Martini $\neq$ Martini

Postoji ključna razlika u ovim nejednakostima, a ona je uvjetovana mogućnošću utvrđivanja s obzirom na kognitivne sposobnosti govornika. Pretpostavimo da govornik stoji na mjestu i iz nekog razloga se ne smije pomaknuti, nego sve svoje prosudbe mora donijeti iz te pozicije. 
Služeći se svojim vidom (što je pretpostavimo jedina metoda na raspolaganju s druge strane prostorije), on može razlikovati čovjeka i psa, ali ne i votku u čaši za Martini i Martini.

Ovo je razlog zašto u jednom slučaju referencija uspijeva, a u drugom ne. Neizraziti sustavi, za razliku od klasičnih ali i probabilističkih, svoju snagu crpe iz načelne precizne nespoznatljivosti ili spoznatljivosti, i $F 1$ je primjer takve upotrebe. Ova tradicionalna načelna nespoznatljivost zove se neizrazitost. Kada je riječ o $F 2$, tu se radi o fenomenu koji bismo mogli nazvati kontekstualna nespoznatljivost ili, u slučaju razlikovanja, kontekstualna nerazlikovnost. Treba uočiti da je neizrazitost svojstvo skupa, a (kontekstualna) nerazlikovnost svojstvo člana skupa s obzirom na neki drugi član ili članove (ova relacija nije simetrična).

Glavna teza može se formulirati ovako: svi slučajevi gdje referencija uspijeva opisom koji nije istinit su slučajevi kontekstualne nerazlikovnosti. Ovo se razlikuje od tradicionalne nespoznatljivosti po tome što su u kontekstu $K 1$ dva fenomena $T 1$ i $T 2$ kontekstualno nerazlikovni, dok su u širem kontekstu $K 2$ oni klasično ili neizrazito različiti.

Kontekstualna nerazlikovnost isto je što i suprapozicija, odnosno fenomen da $\mathrm{u} n$ dimenzija dvije točke zauzimaju istu poziciju (odnosno da je po $n$ osi njihova udaljenost 0 , sukladno metrici prostora), dok je u $n+k$ dimenziji ova udaljenost različita od 0 za neki $k>0$. Ovo se može vizualizirati uz pomoć sljedeće ilustracije. Neka su na nekoj GPS karti dva vozila na istom mjestu. Tada je ovo moguće ili ako je to u stvari jedno te isto vozilo (koje ima dva GPS lokatora) ili pak ako su različiti po nekoj trećoj dimenziji, primjerice tako da se jedno vozilo nalazi na prizemnom parkingu, a drugo na trećem katu.

Ovo nas dovodi do još jednog svojstva kontekstualne nerazlikovnosti koje ju povezuje ali ne i poistovjećuje s neizrazitosti. Mi ni načelno ne možemo ustvrditi činjeničnu razliku kod svih fenomena s kojima operiramo pa se pouzdajemo (ako imamo adekvatno široki kontekst) da je kontekstualna nerazlikovnost za nas ista kao i kontekstualna nerazlikovnost za sugovornika. Na taj način moj pogrešni opis isti je kao i sugovornikov pa nije potrebno provoditi utvrđivanje činjeničnog stanja. Potreba se javlja tek kada ne dijelimo kontekst: u slučaju $S 1$ i $S 2$ to bi bio na primjer slučaj kada je moj sugovornik natočio osobno tom čovjeku votku u tu čašu, pa ima informacije koje ja nemam, i za njegov kontekst više nije nerazlikovno. 
Ovo vodi natrag do nužnih svojstava. Ako su dva predmeta u kontekstu $K$ kontekstualno nerazlikovni, onda su njihova nužna svojstva kontekstualno nerazlikovna. Iz ovoga slijedi da su nužna svojstva tek relativno nužna s obzirom na kontekst. Također, moguće je iščitati i metafizički prioritet: ako su nužna svojstva nužna s obzirom na neki kontekst, onda je nužno svojstvo tog konteksta (koje ga čini različitim od drugih konteksta) upravo skup nužnih svojstava koje definira. Važno pitanje postaje što karakterizira kontekst svih konteksta, ali ovo bi nas odvelo prema već poznatim paradoksima poput Russellovog (van Heijenoort, 1967, 124-125).

\section{Zaključak}

Najveća razlikovnost postoji u najspecifičnijim kontekstima (koji imaju najizrazitije granice), a najmanja u najopćenitijima, odnosno u generalnim. Ovo je važna spoznaja jer nam ona daje tzv. vezno svojstvo za evaluaciju ova dva parametra. Neka je $a$ koeficijent izrazitosti, a $b$ koeficijent razlučivosti, tada vrijedi da za svaki $a$ i $b, a \leq b$, pri čemu su $a$ i $b$ brojevi iz realnog intervala $(0,1)$, gdje 1 predstavlja najveću razlikovnost i najveću izrazitost. Da bismo pokazali zašto koristimo baš relaciju <, a ne samo proporcionalnost, treba uočiti da barem za neke članove neizrazitog skupa (na granici) vrijedi da ako imaju različite funkcije pripadnosti, onda su po njima razlikovni. Drugim riječima, ako pripadnost nekog člana neizrazitom skupu nije 1, onda je to njegovo nužno svojstvo. Pitanje nužnih svojstava bilo je središnjim pitanjem kroz cijeli rad, i prikazali smo međuodnos više razina nužnih svojstava te dali svojevrsnu meta-analizu esencijalizma.

Odnos ovih dvaju koeficijenata i punu formalizaciju ovog sustava ostavljamo za buduće istraživanje. Ovaj rad prvenstveno je posvećen otkrivanju kompleksne motivacije za uvođenje formalnih sustava za analizu usvajanja jezika, s obzirom da oni nude formalizaciju konteksta i međuodnosima u kontekstu, adresirajući pritom neke otvorene probleme filozofije jezika. Prirodna interpretacija semantike ovakvih sustava je vrednovanje s kompleksnim brojevima. Premda je ovo relativno novo područje s računalnim motivacijama (Kosheleva, Kreinovich i Ngamsantivong, 2013), naša motivacija i pristup su specifični po tome što se na ove sustave gleda kroz primarno filozofijske probleme. Međutim, bez obzira na različitu početnu motivaciju, dolazimo do istih zaključaka. 


\section{Literatura}

Donnellan, Keith Sedgwick (1966), »Reference and definite descriptions«, The Philosophical Review, 75(3), str. 281-304.

Donnellan, Keith Sedgwick (1972), »Proper names and identifying descriptions«, u: Davidson, Donald i Harman, Gilbert (ur.), Semantics of Natural Language, Berlin: Springer, str. 356-379. doi: https://doi.org/10.1007/BF00484804

Flach, Peter A. (2012), Machine Learning: The Art and Science of Algorithms that Make Sense of Data, Cambridge: Cambridge University Press.

Hajek, Petr (1998), Metamathematics of Fuzzy Logic, Amsterdam: Kluwer Academic Press.

van Heijenoort, Jan (1967), From Frege to Gödel: A Source Book in Mathematical Logic, 1879-1931, Cambridge: Harvard University Press.

Kant, Immanuel (2007), Critique of Pure Reason, London: Penguin Classics.

Kosheleva, Olga, Kreinovich, Vladik i Ngamsantivong, Thavatchai (2013), »Why complex-valued fuzzy? Why complex values in general? A computational explanation", Proceedings of the IFSA World Congress and NAFIPS Annual Meeting (IFSA/NAFIPS), str. 1233-1236.

doi: http://dx.doi.org/10.1109/IFSA-NAFIPS.2013.6608577

Kripke, Saul (1980), Naming and Necessity, Cambridge: Harvard University Press.

Quine, Willard Van Orman (1980), »Two dogmas of empiricism«, u: Quine, Willard Van Orman (ur.) From a Logical Point of View, Cambridge: Harvard University Press, str. 20-45.

Ross, Timothy (2010), Fuzzy Logic with Engineering Applications, New York: Wiley Press.

Russell, Bertrand (1905), »On denoting«, Mind, 14(46), str. 479-493.

Russell, Stuart i Norvig, Peter (2009), Artificial Intelligence: A Modern Approach, Harlow: Pearsons.

Wittgenstein, Ludwig (1998), Filozofijska istraživanja, Zagreb: Nakladni zavod Globus. 


\section{FUZZY LANGUAGE ACQUISITION}

\section{Sandro Skansi}

In this text we explore the role of fuzziness and essential properties in language acquisition. We define a context and its essential properties via language games and we analyze some classical issues in philosophy of language from the point of view of descriptivism, but with fuzzy description clusters. After our analysis, we propose a complex-valued system capable of reasoning with contextually indistinguishable elements. We leave the full formalization of this system for future research.

Key words: language acquisition, fuzzy sets, indistinguishable set members, contextualism, necessary properties 